\title{
Variação da temperatura e umidade de grãos armazenados em silos com aeração ${ }^{1}$
}

\author{
Ivano A. Devilla², Sandra M. Couto ${ }^{3}$, Sérgio Zolnier ${ }^{4} \&$ Juarez de S. e Silva ${ }^{5}$
}

\author{
1 Parte da Tese de Doutorado do primeiro autor \\ 2 Universidade Estadual de Goiás. UNuCET. Fone: (062) 324-2176. E-mail: devilla@ueg.br (Foto) \\ ${ }^{3}$ UFV. CEP 36571-000, Viçosa, MG. Fone: (031) 3899 1927. E-mail: scouto@mail.ufv.br \\ ${ }^{4}$ UFV. Fone: (031) 3899 1880. E-mail: zolnier@ufv.br \\ ${ }^{5}$ UFV. Fone: (031) 3899 2729. E-mail: desousae@mail.ufv.br
}

Protocolo 126 - 30/8/2002 - Aprovado em 16/02/2004

\begin{abstract}
Resumo: Neste trabalho, estudou-se a variação de temperatura e de umidade em uma massa de grãos de milho armazenada em um silo, durante a aeração do produto, determinando-se o tempo de aeração requerido para se obter uma diferença de temperatura de $3^{\circ} \mathrm{C}$ entre a massa de grãos e o ambiente externo do silo. Inicialmente, os grãos de milho armazenados foram aquecidos utilizando-se equipamentos para aquecimento e umidificação do ar insuflado na massa. $O$ processo de aeração foi realizado com fluxo de ar de $0,0157 \mathrm{~m}^{3} \mathrm{~s}^{-1} \mathrm{~m}^{-2} \mathrm{e}$, com o auxílio de um sistema de aquisição de dados e termopares, registraram-se as temperaturas em diversos pontos da massa de grãos, localizados radialmente a diferentes distâncias horizontais e verticais nas direções norte, sul, leste, oeste. Amostras do produto foram retiradas periodicamente, durante o resfriamento, para determinação da umidade. A redução de temperatura na massa de grãos dependeu da localização do produto no interior do silo, enquanto as maiores reduções de temperatura foram detectadas no produto localizado nas regiões sul e leste, e as menores, nas regiões norte e oeste que, de início, continham o produto em temperaturas mais baixas. A maior redução na temperatura da massa de grãos ocorreu entre 24 e $48 \mathrm{~h}$ de aeração. Um tempo de aeração de aproximadamente $70 \mathrm{~h}$, foi necessário para que a diferença de temperatura entre a massa de grãos e o ambiente externo ao silo fosse igual a $3{ }^{\circ} \mathrm{C}$.
\end{abstract}

Palavras-chave: armazenamento, milho, teor de umidade

\section{Variations of temperature and moisture content of grains stored in bins with aeration}

\begin{abstract}
The temperature and moisture content variations in corn kernels stored in a bin during an aeration process are presented in this work. The aeration time requirements were determined to obtain a temperature difference of $3^{\circ} \mathrm{C}$ between the mass of grains and the external environment. The temperature of the stored grains was increased by submitting the product to a forced flow of moist and pre-heated air before the aeration. Airflow of $0.0157 \mathrm{~m}^{3} \mathrm{~s}^{-1} \mathrm{~m}^{-2}$ was used in the aeration process. Temperatures were recorded at several points inside the grain mass with the aid of thermocouples connected to a data acquisition system. The points were located radially at different horizontal and vertical distances on the North, South, East and West directions. Samples of the product were collected periodically during the process for moisture content determination. The temperature reduction in the mass of grains depended on the location of the product inside the bin. The largest temperature reductions were detected for the product located at South and East, and the smallest for the product at North and West (initially with lower temperature). The largest reduction in the temperature of the mass occurred between 24 and $48 \mathrm{~h}$ of aeration. An aeration time of approximately, $70 \mathrm{~h}$ was necessary to obtain a $3^{\circ} \mathrm{C}$ temperature difference between the mass of grains and the external environment.
\end{abstract}

Key words: storage, corn, moisture content 


\section{INTRODUÇÃO}

A manutenção da qualidade de grãos agrícolas armazenados por longos períodos depende do controle de insetos, fungos e bactérias, que se reproduzem e se desenvolvem no meio (Sun \& Woods, 1997). Uma redução da temperatura da massa de grãos, abaixo de $15{ }^{\circ} \mathrm{C}$, tem sido eficiente na redução da atividade de água dos grãos e, assim, na prevenção do desenvolvimento de insetos e no controle de fungos (Sun \& Woods, 1994; Sun \& Byrne, 1998).

$\mathrm{O}$ teor de umidade de um produto exerce grande influência na variação de temperatura de uma massa de grãos durante a armazenagem (Abbouda et al., 1992; Khankari et al., 1994). Por isso, recomenda-se a secagem e limpeza do produto antes do seu armazenamento, pois esses procedimentos diminuem a ação da microflora na massa de grãos, retardando a velocidade das trocas gasosas e o processo de deterioração natural.

Devido a mudanças climáticas, variações de temperatura também contribuem para a formação de gradientes de temperatura em uma massa de grãos armazenada. Temperaturas diferentes nos ambientes interno e externo de um silo provocam correntes de ar na massa de grãos, que podem induzir a migração de umidade das áreas de altas temperaturas para as de baixas temperaturas. A migração de umidade pode potencializar o desenvolvimento de insetos, fungos e bactérias e iniciar a deterioração do produto (Converse et al., 1973; Brooker et al., 1992; Chang et al., 1993; Casada \& Young, 1994; Chang \& Steele, 1995; Gong et al., 1995).

Srivastava \& Rao (1994) estudando o armazenamento de trigo nas temperaturas de 27,37 e $50^{\circ} \mathrm{C}$ durante 1,3 e 5 meses, concluíram que aumentos de temperatura e do tempo de armazenamento provocam queda na qualidade final do produto armazenado.

A técnica mais empregada para diminuir gradientes de temperatura na massa de grãos e, conseqüentemente, minimizar a migração de umidade, é a aeração (Sauer, 1992; Jayas et al., 1995). Este processo, além de inibir o desenvolvimento de insetos e da microflora, preserva a qualidade do produto e pode até remover odores (Navarro \& Calderon, 1982; Silva et al., 2000).

Calderwood et al. (1984) estudaram o efeito da aeração em arroz armazenado, ao longo de 54 meses, em silos metálicos e concluíram que o controle de insetos foi o principal fator para o sucesso do armazenamento. Neste contexto, a aeração da massa de grãos mostrou-se eficiente para reduzir a temperatura do produto abaixo da temperatura ótima para o desenvolvimento de insetos e proporcionar, ao final do armazenamento, um produto com boa germinação e baixa acidez.

Arthur (1994) estudou grãos de milho armazenados em silos com aeração contínua. Populações de insetos (Sitophilus zeamais e Tribolium castaneum) foram reduzidas em silos que continham sistema de aeração.

Arthur \& Throne (1994) avaliaram a degradação de inseticida metílico em grãos de milho armazenados em silos aerados e não-aerados, chegando à conclusão de que o inseticida se degrada mais rapidamente em silos não-aerados e, também, que a população de insetos nos grãos foi maior nesses silos.
Uma das vantagens do controle de insetos pela manipulação da temperatura na massa de grãos é o menor uso de fumigantes (Reed et al., 2000). Cuperus et al. (1986) relataram que grãos de trigo armazenados sem aeração foram tratados com fumigantes duas vezes mais que aqueles aerados.

Portanto, o conhecimento da variação de temperatura e de umidade em diferentes locais de uma massa de grãos, ao longo de um processo de aeração, pode ser uma ferramenta importante no desenvolvimento e na avaliação de estratégias de controle da aeração para manter os grãos sadios e reduzir os custos com tratamento químico, direcionado para insetos e fungos. Este conhecimento pode, também, ser usado em simulações matemáticas para validar modelos de transferência de calor e de massa em grãos armazenados. Uma vez validado, por meio de simulação (processo rápido, eficiente e de baixo custo) podese obter a resposta do sistema ao ser submetido a diferentes condições (Jia et al., 2001).

Este trabalho foi desenvolvido com o objetivo de estudar as variações de temperatura e de umidade em uma massa de grãos de milho, armazenada em um silo, durante a aeração do produto, e determinar o tempo de aeração requerido para se obter uma diferença de temperatura de $3{ }^{\circ} \mathrm{C}$ entre a massa de grãos e o ambiente externo do silo.

\section{MATERIAL E MÉTODOS}

Este trabalho foi realizado na área de Pré-Processamento de Produtos Agrícolas do Departamento de Engenharia Agrícola, pertencente ao Centro de Ciências Agrárias da Universidade Federal de Viçosa, Viçosa, MG, durante o período de 1 a 12 de julho de 2001. A área está situada a $20^{\circ} 45^{\prime} 45^{\prime \prime}$ latitude sul, $42^{\circ} 52^{\prime} 04^{\prime \prime}$ longitude oeste e altitude de $690 \mathrm{~m}$.

Nos experimentos foram usados grãos de milho (Zea mays L.) adquiridos pelo Centro de Produção da Universidade Federal de Viçosa (safra 2000/2001) com umidade inicial de 21\% b.u. O produto foi submetido a um processo de secagem com ar ambiente forçado, até atingir um teor de umidade de 13\% b.u. O lote continha grãos de diferentes variedades. Alguns parâmetros relacionados com a caracterização do produto (dimensões, massas específicas, aparente e real, e porosidade) foram, então, determinados.

No experimento, utilizou-se um silo metálico cilíndrico (3,6 m de diâmetro e 2,2 $\mathrm{m}$ de altura) de fundo totalmente perfurado, ao qual foi adaptado um sistema de aeração (duto circular, ventilador centrífugo com motor trifásico de $1,5 \mathrm{~kW}$ e diafragma para controle da entrada do ar no ventilador). O duto foi construído com o recobrimento do fundo do silo com chapas metálicas, fazendo-se com que a área de entrada do ar para o interior do silo apresentasse o formato de anel circular com largura de $0,2 \mathrm{~m}$, que foi posicionado a $1,1 \mathrm{~m}$ do centro do silo.

Termopares "tipo T" (AWG 2-24, PVC-PVC - cobreconstantan) foram posicionados em diferentes locais (um fora do silo, na saída de ar do ventilador, e 9 no interior da massa de grãos), conforme ilustra a Figura 1, e depois dispostos nas direções norte-sul e leste-oeste (verdadeiro); no interior do silo foram posicionados nas interseções das alturas de $0,6 \mathrm{e}$ $1,1 \mathrm{~m}$, com as distâncias radiais de 0;0,6;1,2 m (Figura 1). 

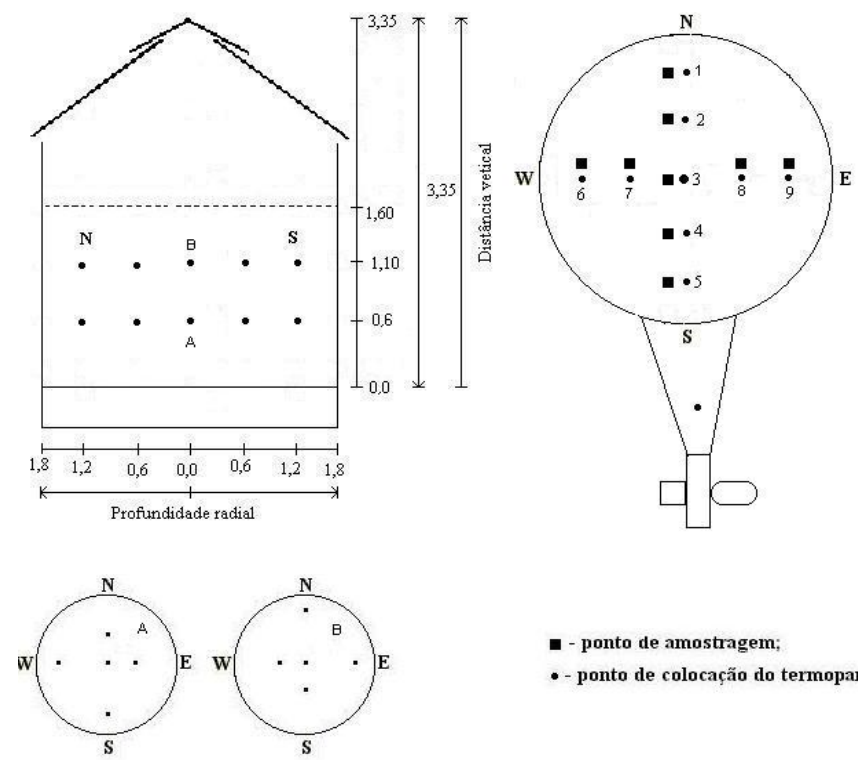

- - ponto de amostragem

- ponto de colocação do termopar

Figura 1. Vistas lateral e superior da localização dos termopares na massa de grãos e vista superior dos pontos de amostragem

Os valores das variáveis pertinentes ao experimento foram registrados com auxílio de um sistema automático de aquisição de dados. Uma placa do tipo plug-in-board (resolução de 16 bits) e uma placa multiplexada (32 canais) foram usadas para o registro das temperaturas nos 11 pontos. A placa principal também foi utilizada para o registro de valores de parâmetros ambientais (temperatura e umidade relativa). Para a coleta dos dados de temperatura e umidade relativa do ar ambiente, utilizouse um sensor termo-higrômetro digital integrado, com precisão de 3\%. A aquisição de dados foi realizada a cada minuto e os dados foram armazenados em um microcomputador.

Depois da instalação dos sensores no silo, este foi carregado até a altura de $1,6 \mathrm{~m}$, com milho ( $13 \%$ b.u.). A superfície da massa de grãos foi aplainada e o produto permaneceu armazenado pelo período de 15 dias.

Dois testes, nos quais se usou aeração contínua da massa de grãos, foram executados; antes de cada teste, a massa de grãos foi aquecida até, aproximadamente, a temperatura média de $28^{\circ} \mathrm{C}$. Para tal, foram usados equipamentos para aquecimento e umidificação do ar que foi insuflado no silo. O equipamento para aquecimento do ar consistiu de um queimador a gás, controlado por um sistema automatizado, que utilizava a temperatura do ar, na saída do ventilador (mantida em $30^{\circ} \mathrm{C}$ ) como parâmetro de decisão. Para a umidificação do ar, usou-se um gerador de vapor composto de um depósito de água instalado no interior de uma fornalha (a lenha, de fogo direto) e de tubos metálicos, para conduzir o vapor até a entrada de ar do ventilador. A umidade relativa do ar foi monitorada para se obter um teor de umidade de equilíbrio dos grãos de $13 \%$ b.u.

Após, aproximadamente, doze horas do aquecimento da massa, executou-se uma amostragem, para determinar o teor de umidade dos grãos, em vários pontos do silo e antes de se iniciar o teste com aeração contínua. Para o teste, ajustou-se o diafragma para que o fluxo de ar na saída do plênum fosse de $0,0157 \mathrm{~m}^{3} \mathrm{~s}^{-1} \mathrm{~m}^{-2}$. O fluxo de ar utilizado equivale a uma vazão de ar de, aproximadamente, $0,02 \mathrm{~m}^{3} \mathrm{~s}^{-1}$. Cada teste de aeração teve início às $12 \mathrm{~h}$, com duração de $96 \mathrm{~h}$, e o intervalo entre os testes foi de $48 \mathrm{~h}$.

Durante os testes foram realizadas amostragens diárias (amostrador de $2 \mathrm{~m}$ de comprimento) para a determinação da umidade. Os pontos de amostragem estavam aproximadamente, $0,07 \mathrm{~m}$ acima dos termopares nos níveis A e B, como mostrado na Figura 1. Na determinação da umidade dos grãos de milho utilizou-se o método-padrão da estufa, $105 \pm 3^{\circ} \mathrm{C}$ por 24 horas, em três repetições, de acordo com as Regras para Análise de Sementes (Brasil, 1992).

\section{RESULTADOS E DISCUSSÃO}

Os valores de parâmetros, considerados relevantes à caracterização do produto utilizado nos experimentos, são apresentados na Tabela 1 .

Tabela 1. Propriedades físicas dos grãos de milho

\begin{tabular}{lc}
\hline Propriedades & Valores \\
\hline Teor de umidade (\% b.u.) & 13 \\
Dimensões principais & \\
$\quad$ Comprimento (mm) & $10,5 \pm 0,8$ \\
$\quad$ Largura (mm) & $8,7 \pm 0,6$ \\
$\quad$ Espessura (mm) & $4,4 \pm 0,5$ \\
Massa específica aparente $\left(\mathrm{kg} \mathrm{m}^{-3}\right)$ & $733 \pm 3$ \\
Massa específica real $\left(\mathrm{kg} \mathrm{m}^{-3}\right)$ & $1264 \pm 6$ \\
Porosidade calculada (\%) & 42 \\
\hline
\end{tabular}

Os valores médios diários da umidade relativa do ar ambiente durante os dois testes de aeração foram de 83,$6 ; 83,9 ; 82,3$; $79,7 \%$ e 82,$6 ; 82,2 ; 82,4 ; 84,4 \%$ para os testes 1 e 2 , respectivamente.

As variações de temperatura e de teor de umidade na massa de grãos, para diferentes direções do silo, durante o processo de aeração, são apresentadas nas Figura $2 \mathrm{~A}, \mathrm{~B}, \mathrm{C}$ e D. As variações são para pontos da massa de grãos localizados nas distâncias verticais de 0,6 e 1,1 m e radiais de 0 (centro do silo), 0,6 e $1,2 \mathrm{~m}$. Os valores diários médios da temperatura ambiente também são apresentados nessas figuras. Observa-se, que as temperaturas e os teores de umidade do produto situado em diferentes pontos do interior do silo, no início da aeração, diferiram entre si. As variações iniciais dos valores de temperatura e de umidade podem ser visualizadas nas Figuras $3 \mathrm{~A}$ e B, respectivamente, nas quais se pode observar, também, valores de temperatura e teor de umidade do produto situado junto à parede do silo (1,8 $\mathrm{m}$ de distância radial).

Nos dois testes constatou-se que, na maioria dos casos, as temperaturas para uma distância vertical de $0,6 \mathrm{~m}$ foram maiores, ou iguais, àquelas para 1,1 m (Figura $3 \mathrm{~A}$ ), em virtude de gradientes de temperatura ocasionados pelo aquecimento da massa de grãos.

O comportamento da temperatura inicial (Figura 3A) na direção radial, difere de acordo com a localização (norte, sul, leste e oeste) do produto no silo. Nas direções sul e leste, à 
A.
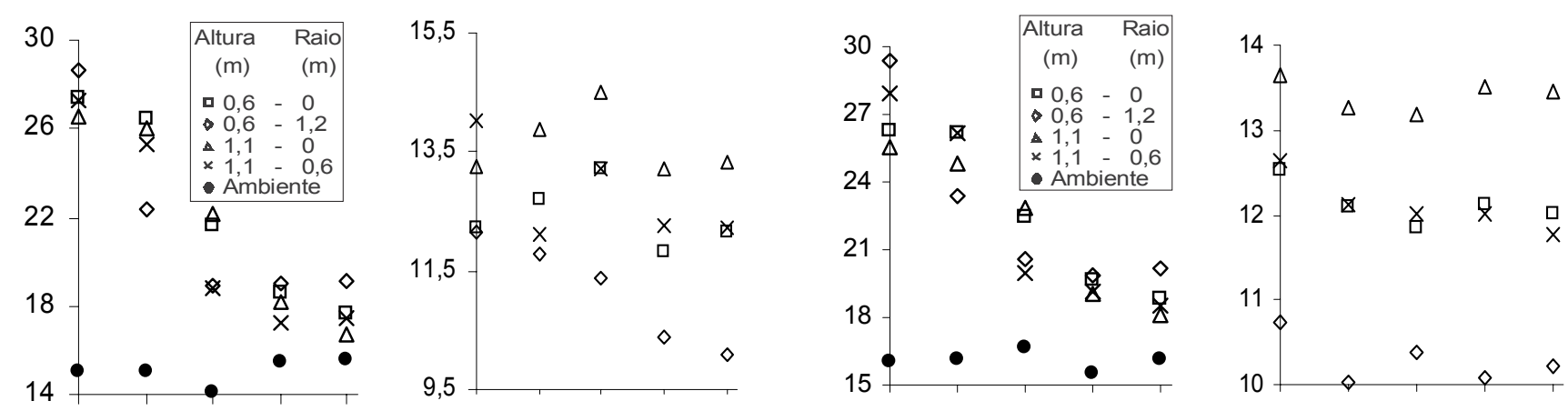

B.
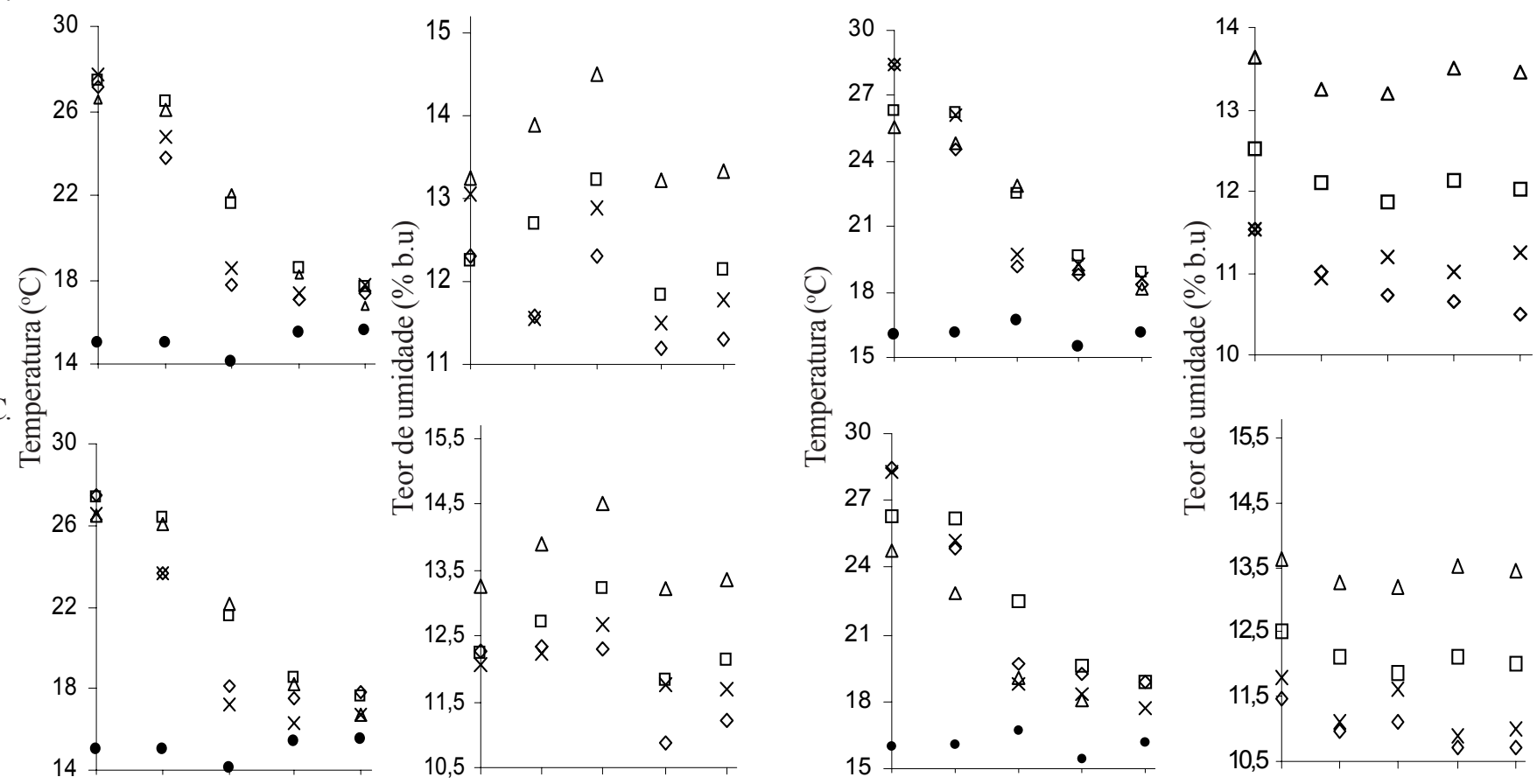

D.
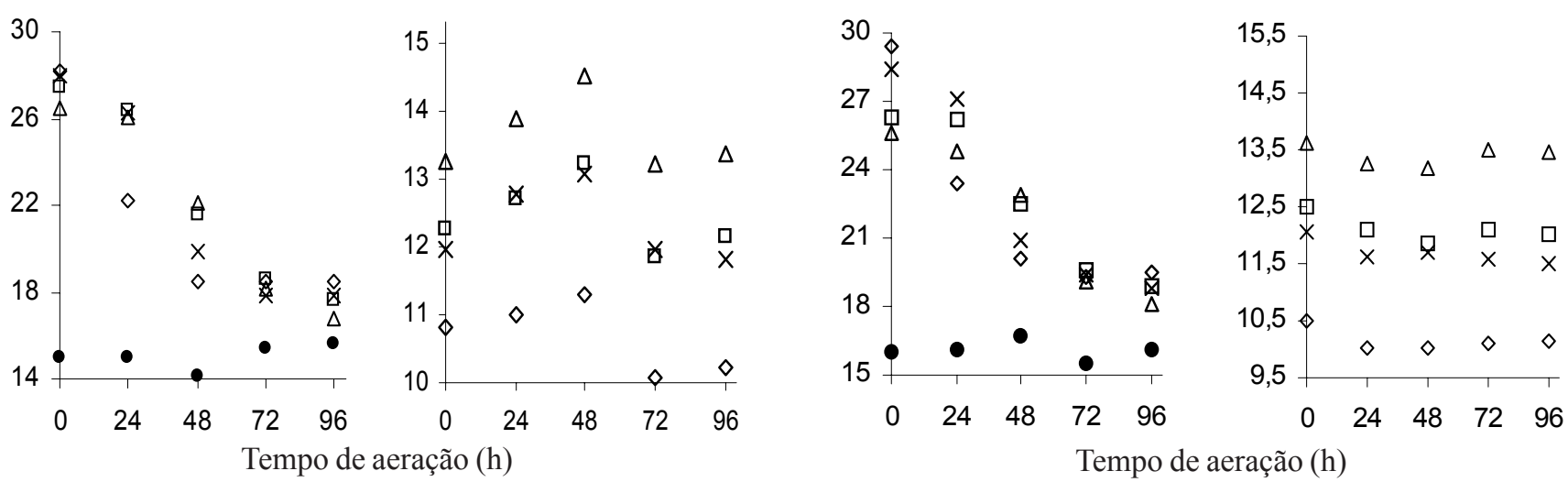

Figura 2. Variação de temperatura e teor de umidade do milho durante a aeração no Teste 1 e 2, para os pontos cardeais: A) Norte, B) Sul, C) Leste e D) Oeste

medida que se aumenta a distância radial, as temperaturas tendem à aumentar, enquanto nas direções norte e oeste tendem a diminuir. Observando-se os valores de temperatura à distância radial de $1,8 \mathrm{~m}$ (próximo à parede do silo) vê-se que, a medida em que se afasta do centro do silo, maior é a influência do ambiente externo nos valores de temperatura dos grãos.

Quando se considerou a temperatura inicial média em todas as distâncias radiais, constatou-se que a região mais quente foi a do leste e a mais fria foi a do norte, nos dois testes de aeração e nas distâncias verticais de 0,6 e de 1,1 m. Explica-se o ocorrido, devido a região leste estar mais exposta aos raios solares, possibilitando maior aquecimento dos grãos. Nos dois testes de aeração e em todas as regiões, as maiores temperaturas iniciais foram determinadas no produto situado a uma distância vertical de $0,6 \mathrm{~m}$, em virtude de estar localizado mais próximo da fonte de aquecimento. 
A.

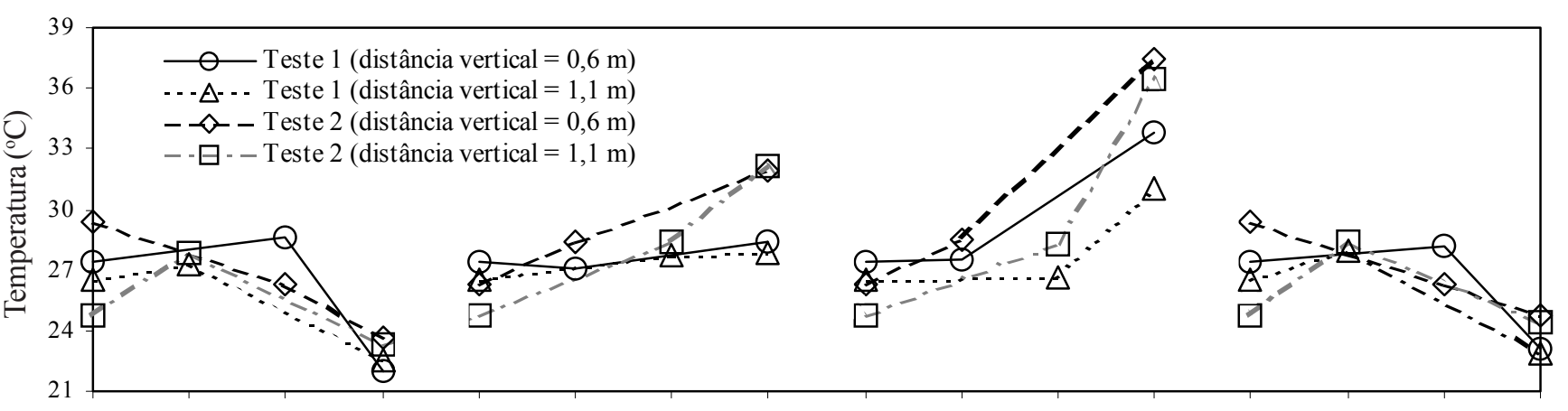

B.

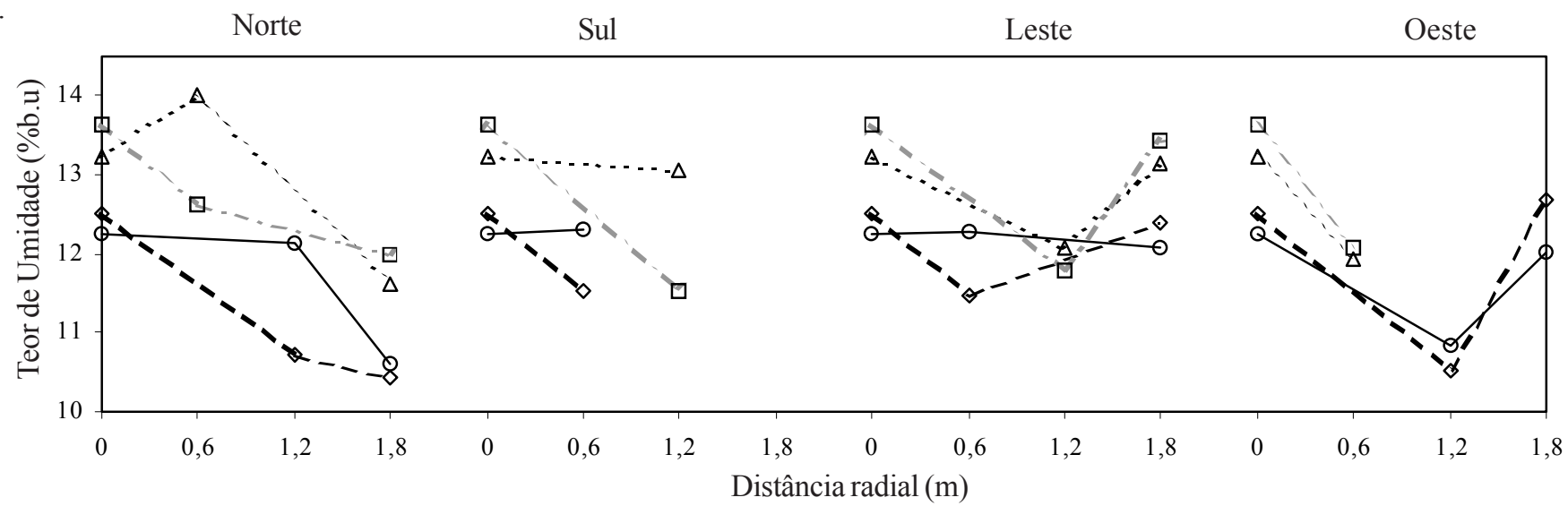

Figura 3. Temperatura (A) e teor de umidade (B) em diferentes pontos da massa de grãos no início da aeração

Nos testes 1 e 2 de aeração, o teor de umidade inicial dos grãos (Figura 3B) situados a uma distância vertical de 1,1 m, em todas as regiões, foi maior que aquele dos grãos situados a 0,6 $\mathrm{m}$, em face de que o aquecimento da massa de grãos provocou redução do teor de umidade nas camadas mais próximas da fonte de calor. Quando se considera o teor de umidade inicial médio em todas as distâncias radiais, vê-se que a região contendo produto com maior teor de umidade foi a sul, no teste 1 de aeração, e a leste no teste 2 . Para as distâncias verticais de $0,6 \mathrm{e} 1,1 \mathrm{~m}$, os menores valores de teor de umidade iniciais foram detectados, respectivamente, nas regiões norte e oeste no teste 1 , e nas regiões norte e sul, no teste 2 .

Portanto, na massa de grãos submetida ao processo de aeração havia gradientes de temperatura e de umidade. Os valores [médio; mínimo; máximo] de temperatura, para toda a massa de grãos foram iguais a $[27,0 \pm 2,6 ; 22,0 ; 33,8]^{\circ} \mathrm{C}$ no teste 1 e $[27,8 \pm 3,7 ; 23,3 ; 37,5]^{\circ} \mathrm{C}$ no teste 2 . Os valores [médio; mínimo; máximo] de teor de umidade para toda a massa de grãos, foram iguais a $[12,4 \pm 0,8 ; 10,6 ; 14,0] \%$ b.u. no teste $1 \mathrm{e}$ $[12,3 \pm 1,0 ; 10,4 ; 13,6] \%$ b.u no teste 2 .

Durante o teste 1 de aeração pôde-se observar, na Figura 2, que a maior redução na temperatura, nas quatro direções avaliadas, ocorreu entre 24 e $48 \mathrm{~h}$ depois do início do processo. É interessante notar que a temperatura do ambiente externo, também apresentada nesta figura, durante este período foi baixa atingindo, no final de $48 \mathrm{~h}, 14^{\circ} \mathrm{C}$, o que, possivelmente, tenha contribuído para um resfriamento mais rápido da massa de grãos. Observa-se, ainda, que neste período as reduções de temperatura no eixo central do silo, nas duas distâncias verticais, foram as menores, sendo a redução da temperatura em pontos localizados a uma distância vertical de $1,1 \mathrm{~m}$ (mais no interior da massa) sempre a menor. Ao final do teste, a temperatura média da massa de grãos era de $17^{\circ} \mathrm{C}$, ou seja, $2^{\circ} \mathrm{C}$ acima da ambiente. De acordo com Silva et al. (2000) a diferença entre a temperatura da massa de grãos e do ambiente deve ser superior a $3{ }^{\circ} \mathrm{C}$ para que seja necessária a aeração dos grãos armazenados.

A redução na temperatura da massa de grãos, ao final do teste 1 de aeração, nas diferentes regiões e posições (radial e vertical) é apresentada na Figura 4.

Observa-se, na Figura 2, durante o teste 2, que a maior redução na temperatura nas quatro direções avaliadas, ocorreu entre 24 e 48 h depois do início do processo. Exceção se faz às reduções de temperatura em pontos situados nas distâncias vertical de $1,1 \mathrm{~m}$ e radial de $0 \mathrm{~m}$; neste caso, as maiores reduções ocorreram depois de $72 \mathrm{~h}$ de aeração, por estarem localizados no centro do silo e mais próximos da superfície da camada de grãos. É interessante notar, também nessa figura, que a temperatura do ambiente externo foi maior que a que vigorava durante o teste 1 . As menores reduções de temperatura ocorreram no eixo central do silo, nas duas distâncias verticais, em virtude de estarem localizados a maior distância do duto de aeração. Ao final do processo de aeração, a temperatura média da massa de grãos era de $19{ }^{\circ} \mathrm{C}$, ou seja, $2,9{ }^{\circ} \mathrm{C}$ acima da temperatura do ambiente. A redução na temperatura da massa de grãos ao final do teste 2 de aeração, nas diferentes regiões e posições (radial e vertical) é apresentada na Figura 4B.

Nos dois testes, as maiores reduções de temperatura foram detectadas no produto localizado nas regiões sul e leste, e as menores, nas regiões norte e oeste que, inicialmente, continham o produto em temperaturas mais baixas. 


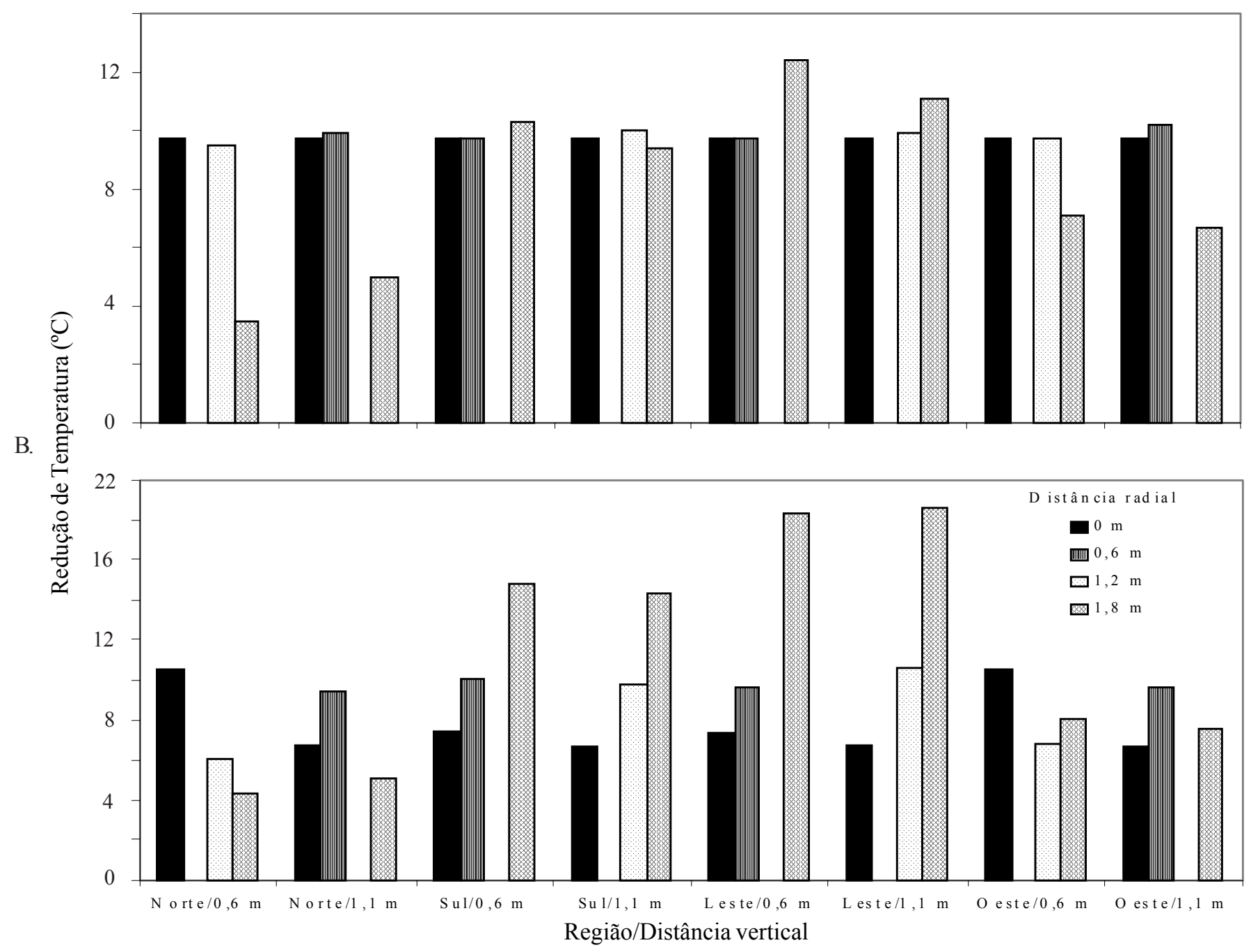

Figura 4. Redução na temperatura da massa de grãos ao final da aeração A - Teste 1; B - Teste 2

Quanto ao teor de umidade do produto, verifica-se a ocorrência de gradientes nas distâncias verticais e, também, radiais, desde o início do teste, devido, possivelmente, à umidificação do ar para o aquecimento do sistema, realizado antes da aeração, e ao posicionamento do sistema de aeração. Na umidificação do ar, as variações radiais no teor de umidade do produto eram esperadas em virtude do posicionamento do sistema de aeração, a uma distância radial de $1,1 \mathrm{~m}$ do centro do silo. Assim, quanto maior era a distância radial, até 1,3 m, menor também era o teor de umidade final do produto, pois este estaria mais próximo à saída do ar.

Os valores médios da temperatura e do teor de umidade da massa de grãos e, ainda, da temperatura do ambiente externo ao silo, durante os dois testes de aeração, são mostrados na Figura 5. Valores relativos à diferença entre a temperatura da massa de grãos e a do ambiente externo, também se encontram nessa figura. Vê-se que a diferença entre as temperaturas atingiu o valor de $3{ }^{\circ} \mathrm{C}$ entre 48 e $72 \mathrm{~h}$ de aeração no teste 1 e entre 72 e $96 \mathrm{~h}$ no teste 2 . A menor temperatura ambiente no decorrer do teste 1 contribuiu para acelerar o resfriamento da massa de grãos.

Aos dados relativos à diferença entre a temperatura da massa de grãos e a do ambiente externo $(\Delta T)$, que aconteceram durante os dias de aeração $(t)$ foram ajustadas equações

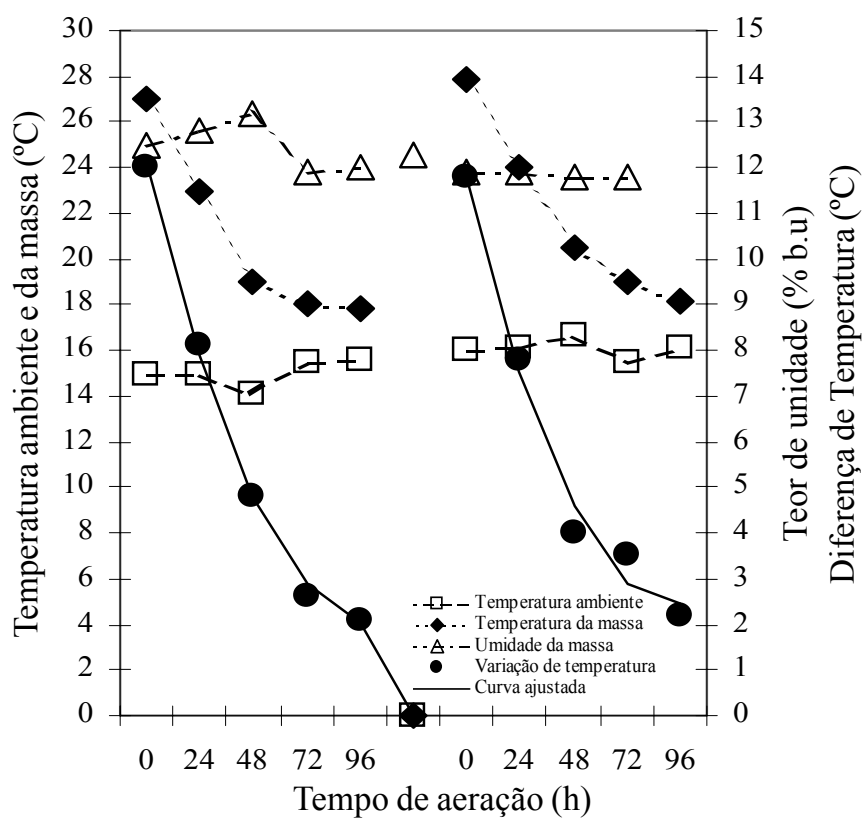

Figura 5. Valores médios da temperatura e do teor de umidade da massa de grãos, da temperatura do ambiente externo ao silo, e diferença de temperatura entre a massa de grãos e o ambiente externo durante os dois testes de aeração 
polinomiais de segundo grau (regressão) cujos coeficientes são apresentados na Tabela 2, acompanhados dos respectivos coeficientes de determinação $\left(\mathrm{R}^{2}\right)$. A representação gráfica dessas equações é mostrada na Figura 5. As equações ajustadas foram usadas para se estimar o tempo de aeração necessário para que a diferença de temperatura entre os dois ambientes fosse igual a $3{ }^{\circ} \mathrm{C}$ e, como resultado, obtiveram-se os valores 69,7 e $69,1 \mathrm{~h}$, respectivamente, para os testes 1 e 2 de aeração.

Tabela 2. Coeficientes das equações ajustadas $\left(\Delta T=\mathrm{At}^{2}+\mathrm{Bt}+\right.$ C) para expressar a diferença entre temperaturas dos grãos e a do ambiente externo $(\Delta T)$ em função do tempo $(\mathrm{t})$ de aeração

\begin{tabular}{ccccc}
\hline Teste de aeração & $\mathrm{A}$ & $\mathrm{B}$ & $\mathrm{C}$ & $\mathrm{R}^{2}$ \\
\hline 1 & $9,850 \times 10^{-4}$ & $-1,993 \times 10^{-1}$ & 12,11 & 0,998 \\
2 & $1,114 \times 10^{-3}$ & $-2,044 \times 10^{-1}$ & 11,81 & 0,989 \\
\hline
\end{tabular}

\section{CONCLUSÕES}

1. A redução de temperatura na massa de grãos dependeu da localização do produto no interior do silo, definida pelas distâncias radial e vertical e pelas direções norte, sul, leste e oeste.

2. À medida que se aumentava a distância radial, as temperaturas dos grãos situados nas direções sul e leste tendiam a aumentar, enquanto as daqueles situados nas direções norte e oeste apresentavam tendência à diminuição.

3. Quando se considerava a temperatura inicial média de todas as distâncias radiais, a região mais quente foi a leste e a mais fria foi a norte, nos dois testes de aeração e nas distâncias verticais de 0,6 e de $1,1 \mathrm{~m}$. Nos dois testes de aeração e em todas as regiões, as maiores temperaturas iniciais foram verificadas no produto situado a uma distância vertical de $0,6 \mathrm{~m}$.

4. As reduções de temperatura do produto tornaram-se menores à medida que a sua localização se aproximava do centro do silo.

5. As maiores reduções de temperatura foram detectadas para o produto localizado nas regiões sul e leste, e as menores nas regiões norte e oeste que, inicialmente, continham o produto em temperaturas mais baixas.

6. A maior redução na temperatura da massa de grãos ocorreu entre 24 e 48 h de aeração.

7. Para a vazão de ar utilizada neste trabalho, um tempo de aeração de, aproximadamente $70 \mathrm{~h}$, foi necessário para que a diferença de temperatura entre a massa de grãos e o ambiente externo ao silo fosse igual a $3{ }^{\circ} \mathrm{C}$.

\section{LITERATURA CITADA}

Abbouda, S.K.; Chung, D.S.; Seib, P.A.; Song, A. Heat and mass transfer in stored milo. Part I. Heat transfer model. Transactions of the ASAE, St. Joseph, v.35, n.5, p.1569-1573, 1992.

Arthur, F.H. Feasibility of using aeration to control insect pests of corn stored in Southeast Georgia: Simulated field test. Journal Economical Entomology, Lanham, v.87, n.5, p.1359$1365,1994$.
Arthur, F.H.; Throne, J.E. Pirimiphos-methyl degradation and insect population growth in aerated and unaerated corn stored in southeast Georgia: Small bin test. Journal Economical Entomology, Lanham, v.87, n.3, p.810-816, 1994.

Brasil. Ministério da Agricultura e Reforma Agrária. Regras para análise de sementes, Brasília, DF, 1992.365p.

Brooker, D.B.; Bakker-Arkema, F.W.; Hall, C.W. Drying and storage of grains and oilseeds. New York : van Nostrand Reinhold, 1992.450p.

Calderwood, D.L.; Cogburn, R.R.; Webb, B.D.; Marchetti, M.A. Aeration of rough rice in long-term storage. Transactions of the ASAE, St Joseph, v.27, n.5, p.1579-1585, 1984.

Casada, M.E.; Young, J.H. Model for heat and moisture transfer in arbitrarily shaped two-dimensional porous media. Transactions of the ASAE, St. Joseph, v.37, n.6, p.19271938, 1994.

Chang, C.S.; Converse, H.H.; Steele, J.L. Modeling of temperature of grain during storage with aeration. Transactions of the ASAE, St. Joseph, v.36, n.2, p.509-519, 1993.

Chang, C.S.; Steele, J.L. Development and evaluation of aeration control strategies for maintaining stored grain quality. Applied Engineering in Agriculture, St. Joseph, v.11, n.4, p.577-582, 1995 .

Converse, H.H.; Graves, A.H.; Chung, D.S. Transient heat transfer within wheat stored in a cylindrical bin. Transactions of the ASAE, St. Joseph, v.2, p.129-133, 1973.

Cuperus, G.W.; Prickett, C.K.; Bloome, P.D.; Pitts, J.T. Insect populations in aerated and unaerated stored wheat in Oklahoma. Journal Kansas Entomology Society, New York, v.59, p.620-627, 1986.

Gong, Z.X.; Devahastin, S.; Mujumdar, A.S. A two-dimensional finite element model for kiln-drying of refractory concrete. Drying Technology, New York, v.13, n.3, p.585-605, 1995.

Jayas, D.S.; White, N.D.G.; Muir, W.E. Stored-grain ecosystems. New York:Marcel Dekker Inc.1995. 756p.

Jia, C.; Sun, D.W.; Cao, C. Computer simulation of temperature changes in a wheat storage bin. Journal of Stored Products Research, London, v.37, p.65-177, 2001.

Khankari, K.K.; Morey, R.V.; Patankar, S.V. Mathematical model for moisture diffusion in stored grain due to temperature gradients. Transactions of the ASAE, St. Joseph, v.37, n.5, p.1591-1604, 1994.

Navarro, S.; Calderon, M. Aeration of grain in subtropical climates. Rome: FAO, 1982, 119p. Agricultural Services Bulletin, n. 52

Reed, C.; Arthur, F.H. Aeration. In: Subramanyam, B.; Hagstrum, D.W. Alternative to pesticides in stored-product IPM. Norwell: Kluwer Academic Publishers, 2000. p.51-72.

Sauer, D.B. Storage of cereal grains and their products. St. Paul, American Association of Cereal Chemists Inc.1992. $615 \mathrm{p}$.

Silva, J.S.; Lacerda Filho, A.F.; Devilla, I.A. Aeração de grãos armazenados. In: Silva, J.S. Secagem e armazenagem de produtos agrícolas. Viçosa: Editora Aprenda Fácil, 2000. p.261-277. 
Srivastava, A.K.; Rao, P.H. Changes in the functional characteristics of wheat during high temperature storage. Journal of Food Science and Technology, Mysore, v.31, n.1, p.36-39, 1994.

Sun, D.W.; Byrne, C. Selection of EMC/ERH isotherm equations for rapeseed. Journal Agricultural Engineering Research, Silsoe, n.69, p.307-315, 1998.
Sun, D.W.; Woods, J.L. Low temperature moisture transfer characteristics of wheat in thin layers. Transactions of the ASAE, St. Joseph, v.37, p.1919-1926, 1994.

Sun, D.W.; Woods, J.L. Deep bed simulation of the cooling of stored grain with ambient air: A test bed for ventilation control strategies. Journal of Stored Products Research, London, v.33, p.299-312, 1997. 